\title{
Characteristics and Co-Admissions of Mothers and Babies Admitted to Residential Parenting Services in the Year Following Birth in NSW: A Linked Population Data Study (2000-2012).
}

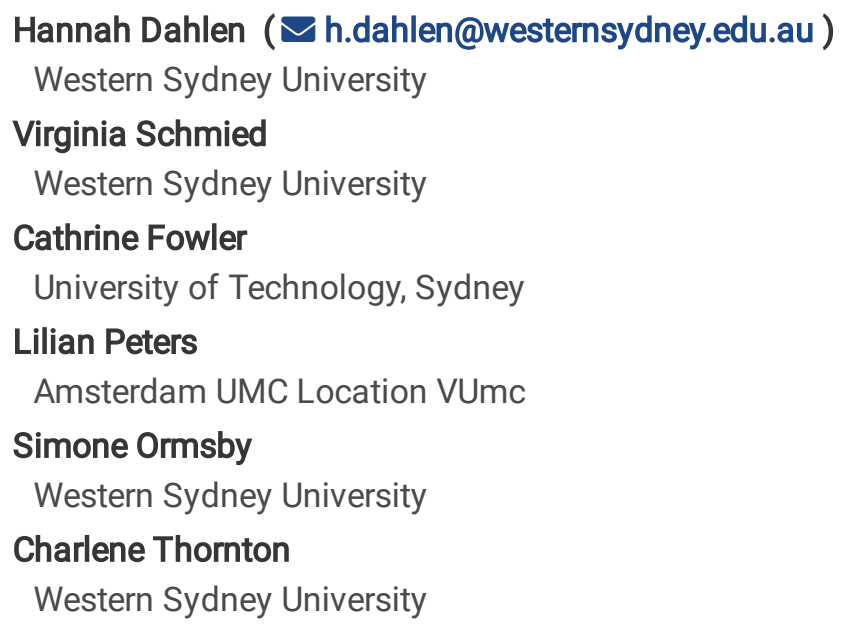

Research Article

Keywords: residential parenting services, early parenting, perinatal mental health, caesarean section

Posted Date: November 29th, 2021

DOI: https://doi.org/10.21203/rs.3.rs-1065990/v1

License: (c) (i) This work is licensed under a Creative Commons Attribution 4.0 International License. Read Full License 


\section{Abstract \\ Background}

There is a tiered healthcare system in Australia to support maternal and child health, including, non-psychiatric day stay and residential parenting services (RPS) such as Tresillian and Karitane (in New South Wales [NSW]). RPS are unique to Australia, and currently there is limited information regarding the healthcare trajectory of women accessing RPS and if they are more likely to have admissions to other health facilities within the first-year post-birth. This study aimed to examine differences in hospital coadmissions for women and babies admitted to RPS in NSW in the year following birth compared to non-RPS admitted women.

\section{Methods}

A linked population data study of all women giving birth in NSW 2000-2012. Statistical differences were calculated using chisquare and student t-tests.

\section{Results}

In total 32071 women and 33035 babies were admitted to RPS with 5191 RPS women also having one or more hospital admissions (7607 admissions). There were 99242 women not admitted to RPS but having hospital admissions (136 771 admissions). Women admitted to RPS who had a co-admission to a hospital were significantly more likely to be older, admitted as a private patient, born in Australia, having their first baby and be socially advantaged ( $\leq .001)$ compared to non-RPS admitted women also having a hospital admission. They also experienced more labour and birth interventions (induction, instrumental birth, caesarean section, epidural, episiotomy), and were more likely to have multiple births, a male infant and babies admitted to Special Care Nursery/Neonatal Intensive Care $(p \leq .001)$. Additionally, these women were more likely to have another admission for mental health and behavioural disorders $(p \leq .001)$, and this appeared to increase over time. There was no between cohort differences regarding the number of women admitted to a psychiatric facility; however, women attending RPS were more likely to have mood affective, or behavioural and personality disorder diagnoses.

\section{Conclusion}

Women accessing RPS in the year post-birth were more socially advantaged, had higher birth intervention and more coadmissions and treatment for mental health disorders than those not accessing RPS. More research is needed into the impact of birth intervention and mental health issues on subsequent parenting difficulties.

\section{Background}

In Australia there is a tiered system of health services (primary, secondary, tertiary) to support parents navigating early parenting difficulties. These include, non-psychiatric day stay and residential parenting services (RPS) such as Tresillian and Karitane (in NSW). All Australian states and territories, except for Tasmania and the Northern Territory, have at least one RPS. In NSW (Australia's most populace state), 7453 women accessed RPS over the 2018-2019 timeframe, of which 5793 attended Tresillian (three units), and 1660, Karitane (two centres) (1, 2); representing 7.8\% of the NSW birthing population (3). During 2020/2021, Tresillian RPS admissions decreased slightly to 5699 (personal communication) as services remained open during the COVID-19 lockdowns to further assist parents cut off from their typical social support networks, however some hesitancy to attend facilities was noted. In the same time period, Karitane also reported lower numbers (1224, personal communication), as the service was transitioned to a virtual residential unit (4). The range of RPS services provided include support with feeding, settling, infant caretaking skills and adjustment to parenting $(5,6)$. More recently, an increased focus has also been placed upon psychosocial assessment and intervention (7), parental self-efficacy and parent-infant relationship development (8). 
Poor mental health in the perinatal period is a global problem (9). Recent Australian estimates for the occurrence of perinatal depression and anxiety are reported to be $20 \%$ for mothers and $10 \%$ for fathers (10). Detrimental consequences include risk of self-harm, poor physical health, breakdown in relationships, social withdrawal, unhappiness in the parental role and, for some, lowered capacity to care for their infant $(9,11-14)$. A small proportion of the perinatal population experience a severe mental health disorder requiring admission to an inpatient psychiatric unit or mother-baby psychiatric unit. Christl et al. (2015) report that the most common primary diagnosis for women admitted to mother-baby psychiatric inpatient units is a major depressive disorder, with more severe illness (schizophrenia and other psychotic disorders) accounting for between 20 and $40 \%$ of admissions (15). While rates vary, many women admitted to hospital for mental health conditions have a history of mental illness (16). This is a crucial concern because research shows that the early years of life strongly influence infant and childhood development $(17,18)$. Poorer cognitive functioning; language impairment; and physical, psychosocial, emotional and behavioural problems have been identified in infants of women with perinatal mental health concerns (19-24).

In most instances RPS are led by nurses with support from multidisciplinary teams including paediatricians, psychologists and counsellors. While some of these services have been utilised for over 100 years, there has been limited research examining the characteristics of parents utilising RPS (25-27). Findings from our recent population-based linkage study however identified that women accessing RPS services within the first-year post-birth were more socially advantaged, and they had higher rates of birth intervention. In addition, over the ten-year timeframe examined, there was a significant increase in the proportion of women admitted to RPS that had instrumental births (28). Other studies have similarly identified that women who have birth interventions are more likely to be admitted to RPS $(29,30)$, and that significant levels of birth trauma are often associated with labour and birth complexity as well as the use of interventions $(31,32)$. It follows that these outcomes contribute towards parenting stress and impact upon postpartum depression (31).

To date, no studies have examined whether the health care trajectories of women admitted to RPS that also have hospital coadmissions within the 12 months following birth differ from non-RPS admitted women having hospital admissions during the same timeframe. This paper therefore explores the clinical characteristics (pregnancy/birth complications, obstetric interventions, postpartum physical/mental health), demographics (parity, age, residence and health insurance status) and co-admissions of women and infants admitted to RPS in NSW during the period from 2000 to 2012 compared to those not admitted to RPS but also having a hospital admission within 12 months following birth.

\section{Methods}

Ethical approval was obtained from the NSW Population and Health Services Research Ethics Committee, HREC/10/CIPHS/96.

\section{Data Sources}

Data were obtained over the timeframe from January 1st 2000 to December 31st 2011 from the NSW Centre for Health Record Linkage ( $\mathrm{CHeReL}$ ) for which the following datasets were selected and linked: 1. Pregnancy and birth data provided by the NSW Ministry of Health from the Perinatal Data Collection (PDC), which contains statistics on all births of greater than 400 grams birth weight and/or 20 completed weeks gestation, amounting to approximately one third of all Australian births annually. 2. The Admitted Patient Data Collection (APDC), which records all admitted patient services provided by NSW Public Hospitals, Public Psychiatric Hospitals, Public Multi-Purpose Services, Private Hospitals, and Private Day Procedures Centres. 3. Mortality data from both the APDC (discharge status) and the NSW Registry of Births, Deaths and Marriages (RBDM, death data). Bureau of Statistics Socio-Economic Indexes for Areas (SEIFA) codes were then applied to the cohorts to establish socio-economic and education status (33). Probabilistic data linkage techniques were utilised for data linkage, whereby probabilistic record linkage software assigned a 'linkage weight' to pairs of records. For example, records that match perfectly or nearly perfectly on first name, surname, date of birth and address have a high linkage weight indicative of a probable match, whereas records matching only on date of birth have a low linkage weight (possible mismatch). This technique has been shown to have a false positive rate of $0.3 \%$ (34). De-identified datasets were provided for analysis.

Subjects 
Two cohorts were created: Cohort 1 included all women who had an admission to a RPS as well as a further admission/s to a NSW hospital within the 12-month period following birth. These women were identified utilising Tresillian and Karitane codes. Cohort 2 was comprised of all women who had a hospital admission in the same time period but not a RPS admission.

Admissions to psychiatric facilities were also obtained from the APDC. These sub-cohorts included any admissions within the time frame of the study and were not limited to the 12-month period following birth, due to the small sample size that would have obtained. Data from subsets of these cohorts has also been provided in our previous study (28).

\section{Outcomes}

Maternal antenatal, birth and neonatal data were extracted, including variables such as mode of birth, birth weight, parity, the presence of maternal hypertension or diabetes, and perinatal mortality. Gestation was recorded at birth (delivery gestation), as well as that obtained from the first antenatal appointment (booking gestation), which typically is calculated from the woman's menstrual history, and/or the size estimate at the routine 12-13-week scan. International Classification of Diseases (ICD-10-AM) codes (35) and the Commonwealth Medicare Benefits Schedule procedure codes (36) were used for grouping of admission data. Diagnoses were obtained from both the primary coding and additional coding combined.

\section{Data analysis}

The analyses between the two cohorts were conducted utilising contingency tables. Statistical differences were calculated with chi-square tests. Continuous variables were compared with student t-tests when normally distributed. Taking into account the size of the cohort and the number of analyses undertaken, results were considered significant at the level $p \leq 0.01$. Analysis was undertaken with IBM SPSS v.23®.

\section{Results}

In cohort 1, 32071 women and 33035 babies were admitted to RPS with 5191 (16.2\%) of these women also having a hospital admission (7607 admissions). In cohort 2, 99242 women not admitted to RPS had hospital admissions (136 771 admissions). These admissions occurred in 382 facilities, $51.3 \%$ of which were public facilities.

Comparisons between cohorts with respect to demographics identified the following significant differences (Table 1). Women in cohort 1 were older, and more likely to be Australian born, classified as a private hospital patient, having their first baby, better educated and socially advantaged than women in cohort $2(p \leq 0.001)$.

\section{Table 1: Demographic profile of cohort 1 compared to cohort 2}

\begin{tabular}{|c|c|c|c|}
\hline \multirow[t]{2}{*}{ Demographic } & $\begin{array}{l}\text { Residential (Cohort } \\
\text { 1) }\end{array}$ & $\begin{array}{l}\text { Non- } \\
\text { residential (Cohort 2) }\end{array}$ & P value \\
\hline & $n=5191$ & $\mathrm{n}=99242$ & \\
\hline Age & $30.5(5.7)$ & $29.4(6.1)$ & $\leq 0.001$ \\
\hline Private patient & $10.4 \%$ & $7.07 \%$ & $\leq 0.001$ \\
\hline Australian born & $80.6 \%$ & $75.3 \%$ & $\leq 0.001$ \\
\hline Nulliparous & $83.2 \%$ & $66.2 \%$ & $\leq 0.001$ \\
\hline $\begin{array}{l}\text { SEIFA* }\left(>6^{\text {th }} \text { decile for index of socio-economic advantage \& }\right. \\
\text { disadvantage })\end{array}$ & $67.5 \%$ & $50.0 \%$ & $\leq 0.001$ \\
\hline SEIFA* $\left(>6^{\text {th }}\right.$ decile for index of education $\&$ occupation & $61.8 \%$ & $51.2 \%$ & $\leq 0.001$ \\
\hline
\end{tabular}

- Data are mean $\pm(S D)$ or $(\%)$ of cases within groups

*SEIFA deciles range from 1 (lowest) to 10 (highest), with $>6^{\text {th }}$ representing areas of above average socio-economic advantage/higher education \& skilled occupation status 
With respect to maternal perinatal and neonatal outcomes (Table 2), women in cohort 1 were significantly more likely to have had a multiple birth, induction of labour, episiotomy, instrumental birth, caesarean section, and an epidural or some other type of pain relief. They were also more likely than women in Cohort 2 to have a male infant and a baby admitted to Special Care Nursery/Neonatal Intensive Care (SCN/NICU). They were however much less likely to smoke and have a baby die $(p \leq 0.001)$.

Table 2: Maternal perinatal and neonatal birth outcomes 


\begin{tabular}{|c|c|c|c|}
\hline Variable & $\begin{array}{l}\text { Residential women } \\
\text { (Cohort 1) } \\
\mathrm{n}=5191\end{array}$ & $\begin{array}{l}\text { Non-residential women (Cohort 2) } \\
\mathrm{n}=99242\end{array}$ & $P$ value \\
\hline Booking gestation & $9.8(5.5)$ & $10.6(6.6)$ & 0.03 \\
\hline Plurality (singleton) & $94.4 \%$ & $97.8 \%$ & $\leq 0.001$ \\
\hline Hypertension & $4.9 \%$ & $4.7 \%$ & 0.42 \\
\hline Diabetes & $5.4 \%$ & $5.3 \%$ & 0.97 \\
\hline Smoking during pregnancy & $9.8 \%$ & $18.6 \%$ & $\leq 0.001$ \\
\hline Delivery gestation & 38. $5(2.86)$ & $38.6(2.99)$ & 0.44 \\
\hline Induction & $31.4 \%$ & $29.3 \%$ & $\leq 0.001$ \\
\hline \multicolumn{4}{|l|}{ Delivery type } \\
\hline - Normal vaginal & $46.0 \%$ & $53.6 \%$ & $\leq 0.001$ \\
\hline - Forceps vaginal & $7.1 \%$ & $5.4 \%$ & $\leq 0.001$ \\
\hline - Ventouse vaginal & $11.9 \%$ & $8.9 \%$ & $\leq 0.001$ \\
\hline - Vaginal breech & $1.2 \%$ & $1.1 \%$ & 0.32 \\
\hline - Caesarean section & $33.8 \%$ & $31.0 \%$ & $\leq 0.001$ \\
\hline - Elective & $46.9 \%$ & $46.2 \%$ & 0.60 \\
\hline - Emergency & $53.1 \%$ & $53.8 \%$ & 0.60 \\
\hline \multicolumn{4}{|l|}{ Pain relief (\% women who laboured) } \\
\hline - None & $8.2 \%$ & $12.3 \%$ & $\leq 0.001$ \\
\hline - Epidural & $33.6 \%$ & $22.9 \%$ & $\leq 0.001$ \\
\hline Episiotomy (\% of vaginal births) & $26.6 \%$ & $20.0 \%$ & $\leq 0.001$ \\
\hline Male sex & $55.0 \%$ & $51.8 \%$ & $\leq 0.001$ \\
\hline Birth weight & $3261.2(700.85)$ & $3269.2(713.70)$ & 0.42 \\
\hline Apgar $<7$ & $3.6 \%$ & $4.4 \%$ & 0.004 \\
\hline Admitted SCN/NICU & $24.6 \%$ & $22.2 \%$ & $\leq 0.001$ \\
\hline Resuscitation any form & $47.9 \%$ & $46.1 \%$ & 0.01 \\
\hline $\begin{array}{l}\text { Perinatal Mortality Rate } \\
\text { (Within } 42 \text { days of birth) }\end{array}$ & 17.0/1000 births & 24.4/1000 births & $\leq 0.001$ \\
\hline $\begin{array}{l}\text { Maternal Mortality rate } \\
\text { (Within } 12 \text { months of birth) }\end{array}$ & $5.8 / 10000$ births & $11.0 / 10000$ births & 0.40 \\
\hline
\end{tabular}

- Data are mean $\pm(S D)$, (\%) of cases within groups or specified fractions 
In terms of hospital admissions (Table 3), women in cohort 1 were significantly more likely to have an admission during the year following birth for mental and behavioural disorders, malignant neoplasms, and diseases of the musculoskeletal system and connective tissues (ICD-10-AM). They were less likely to have had another baby within the 12-month period following the index pregnancy compared to women in cohort $2(\mathrm{p} \leq 0.001)$.

Table 3. Diagnostic codes (ICD-10-AM) recorded for maternal readmission in the 12-month period following delivery 


\begin{tabular}{|c|c|c|c|c|}
\hline ICD-10-AM Grouping Name & Codes & $\begin{array}{l}\text { Cohort } 1 \\
\mathrm{n}=5191\end{array}$ & $\begin{array}{l}\text { Cohort } 2 \\
n=99242\end{array}$ & $P$ value \\
\hline Certain infectious \& parasitic diseases & $\begin{array}{l}\text { A00- } \\
\text { B99 }\end{array}$ & $2.34 \%$ & $2.72 \%$ & 0.02 \\
\hline Malignant neoplasms & $\begin{array}{l}\mathrm{C} 00- \\
\mathrm{C} 96\end{array}$ & $1.58 \%$ & $1.33 \%$ & $\leq 0.001$ \\
\hline In situ neoplasms & $\begin{array}{l}\text { D00- } \\
\text { D09 }\end{array}$ & $0.31 \%$ & $0.47 \%$ & 0.008 \\
\hline Benign Neoplasms & $\begin{array}{l}\text { D10- } \\
\text { D36 }\end{array}$ & $1.03 \%$ & $0.89 \%$ & 0.013 \\
\hline Neoplasms of uncertain or unknown behaviour & $\begin{array}{l}\text { D37- } \\
\text { D48 }\end{array}$ & $1.27 \%$ & $1.22 \%$ & 0.2 \\
\hline $\begin{array}{l}\text { Diseases of the blood \& certain blood forming organs \& certain disorders } \\
\text { involving the immune mechanism }\end{array}$ & $\begin{array}{l}\text { D } 50- \\
\text { D89 }\end{array}$ & $0.68 \%$ & $0.84 \%$ & 0.07 \\
\hline Endocrine, nutritional \& metabolic diseases & $\begin{array}{l}\text { E00- } \\
\text { E89 }\end{array}$ & $1.26 \%$ & $1.40 \%$ & 0.36 \\
\hline Mental \& behavioural disorders & $\begin{array}{l}\text { F00- } \\
\text { F99 }\end{array}$ & $8.43 \%$ & $4.18 \%$ & $\leq 0.001$ \\
\hline Diseases of the nervous system & $\begin{array}{l}\text { G00- } \\
\text { G99 }\end{array}$ & $0.97 \%$ & $0.93 \%$ & 0.3 \\
\hline Diseases of the eye $\&$ adnexa & $\begin{array}{l}\mathrm{H} 00- \\
\mathrm{H} 59\end{array}$ & $0.27 \%$ & $0.30 \%$ & 0.85 \\
\hline Diseases of the ear \& mastoid process & $\begin{array}{l}\mathrm{H} 60- \\
\mathrm{H} 95\end{array}$ & $0.09 \%$ & $0.17 \%$ & 0.03 \\
\hline Diseases of the circulatory process & $\begin{array}{l}100- \\
199\end{array}$ & $1.59 \%$ & $1.65 \%$ & 0.94 \\
\hline Diseases of the respiratory system & $\begin{array}{l}\text { J00- } \\
\text { J99 }\end{array}$ & $1.40 \%$ & $1.61 \%$ & 0.14 \\
\hline Diseases of the digestive system & $\begin{array}{l}\text { K00- } \\
\text { K93 }\end{array}$ & $7.82 \%$ & $8.07 \%$ & 0.63 \\
\hline Diseases of the skin \& subcutaneous tissue & $\begin{array}{l}\text { L00- } \\
\text { L99 }\end{array}$ & $0.93 \%$ & $1.01 \%$ & 0.68 \\
\hline Diseases of the musculoskeletal system \& connective tissue & $\begin{array}{l}\text { M00- } \\
\text { M99 }\end{array}$ & $1.63 \%$ & $1.38 \%$ & $\leq 0.001$ \\
\hline Diseases of the genito-urinary system & $\begin{array}{l}\text { N00- } \\
\text { N99 }\end{array}$ & $6.30 \%$ & $6.33 \%$ & 0.15 \\
\hline Pregnancy, childbirth \& the puerperium & $\begin{array}{l}\text { O00- } \\
099\end{array}$ & $19.38 \%$ & $20.87 \%$ & $\leq 0.001$ \\
\hline Congenital malformations \& chromosomal abnormalities & $\begin{array}{l}\text { Q00- } \\
\text { Q99 }\end{array}$ & $0.30 \%$ & $0.27 \%$ & 0.32 \\
\hline $\begin{array}{l}\text { Symptoms, signs \& abnormal findings, clinical \& laboratory findings not } \\
\text { elsewhere classified }\end{array}$ & $\begin{array}{l}\text { R00- } \\
\text { R99 }\end{array}$ & $4.65 \%$ & $4.56 \%$ & 0.06 \\
\hline Injury, poisoning \& certain other consequences of external causes & $\begin{array}{l}\text { S00- } \\
\text { T98 }\end{array}$ & $2.47 \%$ & $2.74 \%$ & 0.22 \\
\hline External cause of morbidity \& mortality & $\begin{array}{l}\text { U50- } \\
\text { Y98 }\end{array}$ & $6.44 \%$ & $6.51 \%$ & 0.22 \\
\hline
\end{tabular}


-ICD-10-AM -International Statistical Classification of Diseases \& Related Health Problems, Tenth Revision, Australian Modification (ICD-10-AM) used to classify diseases \& other health problems

When comparing the 10 most commonly occurring procedures provided to the cohorts (Table 4), we found women in cohort 1 were significantly more likely to have had anaesthesia, major surgery (of all body systems apart from gynaecological), allied health intervention, chemotherapy and psychological therapy $(p \leq 0.001)$.

Table 4: Ten most commonly occurring procedures conducted on admitted women in the 12-month period following delivery

\begin{tabular}{|llll|}
\hline Procedure classification & Cohort 1 & Cohort 2 & P value \\
& $\mathbf{n = 1 4 6 9 9}$ & $\mathbf{n = 2 6 4 8 4 9}$ & \\
\hline Anaesthesia & $20.3 \%$ & $21.5 \%$ & $\leq \mathbf{0 . 0 0 1}$ \\
\hline Major surgical (all body systems except gynaecological) & $9.53 \%$ & $10.44 \%$ & $\leq \mathbf{0 . 0 0 1}$ \\
\hline Diagnostic procedures & $7.86 \%$ & $7.84 \%$ & 0.01 \\
\hline Allied health intervention & $7.8 \%$ & $6.7 \%$ & $\leq \mathbf{0 . 0 0 1}$ \\
\hline Psychological therapy & $4.54 \%$ & $1.15 \%$ & $\leq \mathbf{0 . 0 0 1}$ \\
\hline Minor surgical (all body systems except gynaecological & $1.97 \%$ & $2.13 \%$ & 0.18 \\
\hline Dental & $1.8 \%$ & $1.5 \%$ & $\mathbf{0 . 0 0 8}$ \\
\hline Transfusion & $0.5 \%$ & $0.7 \%$ & $\mathbf{0 . 0 0 4}$ \\
\hline Cosmetic procedures & $0.30 \%$ & $0.28 \%$ & 0.78 \\
\hline Chemotherapy & $0.2 \%$ & $0.1 \%$ & $\leq \mathbf{0 . 0 0 1}$ \\
\hline
\end{tabular}

- Data are (\%) within code classification

Examination of the incidence of gynaecological and obstetric procedures conducted (Table 5) identified women in cohort 1 experienced significantly more IVF procedures $(p=0.004)$; and significantly less contraception/sterilisations, termination of pregnancies, and obstetric interventions (insertion of suture/diagnostic procedure/postpartum dilatation \& curettage) compared to cohort $2(p \leq 0.001)$.

Table 5: Gynaecological and obstetric procedures conducted on women in the 12-month period following delivery 


\begin{tabular}{|c|c|c|c|c|}
\hline Classification & Procedure & $\begin{array}{l}\text { Cohort } \\
1 \\
n=14 \\
699\end{array}$ & $\begin{array}{l}\text { Cohort } \\
2 \\
n=264 \\
849\end{array}$ & $P$ value \\
\hline Minor surgical & & $0.28 \%$ & $0.36 \%$ & 0.14 \\
\hline \multirow[t]{12}{*}{ Major surgical } & Oophorectomy/salpingectomy/ectopic pregnancy removal & $0.22 \%$ & $0.34 \%$ & 0.03 \\
\hline & Hysterectomy & $0.10 \%$ & $0.12 \%$ & 0.70 \\
\hline & Diagnostic procedure & $0.40 \%$ & $0.51 \%$ & 0.08 \\
\hline & Myomectomy/cystectomy & $0.28 \%$ & $0.31 \%$ & 0.58 \\
\hline & LLETZ procedure/ovarian/uterine/pelvic/vaginal lesions & $1.18 \%$ & $1.24 \%$ & 0.50 \\
\hline & $\begin{array}{l}\text { Repair of rectal } \\
\text { prolapse/rectocele/anorectalplasty/anoplasty/sphincterplasty/anal } \\
\text { repair/anal fissure/thrombus/abscess/anal examination/insertion } \\
\text { of anal stimulator/repair of anal fistula }\end{array}$ & $0.33 \%$ & $0.32 \%$ & 0.84 \\
\hline & $\begin{array}{l}\text { Vagina/uterus/pelvic floor/urethral/cervix repair/vaginal orifice } \\
\text { surgery/perineal haematoma/perineal repair }\end{array}$ & $0.77 \%$ & $0.68 \%$ & 0.24 \\
\hline & Caesarean section wound haematoma & $0.03 \%$ & $0.09 \%$ & 0.05 \\
\hline & Cystocele/enterocele/repair for incontinence & $0.14 \%$ & $0.11 \%$ & 0.33 \\
\hline & Vulvoplasty/cliteroplasty & $0.12 \%$ & $0.08 \%$ & 0.07 \\
\hline & Other uterine procedures & $0.06 \%$ & $0.07 \%$ & 0.49 \\
\hline & Other female reproductive procedures & $0.35 \%$ & $0.39 \%$ & 0.48 \\
\hline Contracept/sterilisation & & $0.69 \%$ & $1.61 \%$ & $\leq 0.001$ \\
\hline IVF & & $1.86 \%$ & $1.56 \%$ & 0.004 \\
\hline $\begin{array}{l}\text { Termination/dilatation } \\
\text { and curettage }\end{array}$ & & $4.00 \%$ & $5.13 \%$ & $\leq 0.001$ \\
\hline Obstetric & $\begin{array}{l}\text { Insertion of suture/diagnostic procedure/postpartum dilatation \& } \\
\text { curettage }\end{array}$ & $3.31 \%$ & $4.13 \%$ & $\leq 0.001$ \\
\hline
\end{tabular}

\section{- Data are (\%) within code classification}

When further examination of admission codes was conducted for maternal mental and behavioural disorders (Table 6), we found mood affective disorders; neurotic, stress-related and somatoform disorders; behavioural syndromes associated with psychological disturbances and physical factors; and personality and behaviour disorders were significantly more common in cohort 1 ( $\mathrm{p} \leq 0.001)$. This was most striking for mood affected disorders ( $5.4 \%$ vs $2.4 \%)$, behavioural syndromes $(4.3 \%$ vs $1.2 \%)$, and neurotic, stress-related and somatoform disorders (4.5\% vs $1.8 \%)$.

Table 6: Mental and behavioural disorders (F00-F99) compared between cohort 1 and 2 


\begin{tabular}{|c|c|c|c|c|}
\hline ICD-10 Mental \& behavioural disorders Grouping Name & Codes & $\begin{array}{l}\text { Cohort } \\
1\end{array}$ & $\begin{array}{l}\text { Cohort } \\
2\end{array}$ & $P$ value \\
\hline Mental \& behavioural issues due to use of alcohol \& drugs & $\begin{array}{l}\text { F10- } \\
\text { F19 }\end{array}$ & $2.8 \%$ & $2.7 \%$ & 0.11 \\
\hline Schizophrenia, schizotypal \& delusional disorders & $\begin{array}{l}\text { F20- } \\
\text { F29 }\end{array}$ & $0.7 \%$ & $0.8 \%$ & 0.9 \\
\hline $\begin{array}{l}\text { Mood affective disorders (Mania, bipolar affective disorder, depressive disorder, } \\
\text { mood disorders) }\end{array}$ & $\begin{array}{l}\text { F30- } \\
\text { F39 }\end{array}$ & $5.4 \%$ & $2.4 \%$ & $\leq 0.001$ \\
\hline $\begin{array}{l}\text { Neurotic, stress-related \& somatoform disorders (Phobias, anxiety disorders, } \\
\text { somatoform disorders, neurotic disorders) }\end{array}$ & $\begin{array}{l}\text { F40- } \\
\text { F48 }\end{array}$ & $4.5 \%$ & $1.8 \%$ & $<0.001$ \\
\hline $\begin{array}{l}\text { Behavioural syndromes associated with psychological disturbances \& physical } \\
\text { factors (nonorganic sleep disorders, sexual dysfunction, mental \& behavioural } \\
\text { disorders associated with the puerperium, harmful use of non-dependence } \\
\text { substances) }\end{array}$ & $\begin{array}{l}\text { F50- } \\
\text { F59 }\end{array}$ & $4.3 \%$ & $1.2 \%$ & $\leq 0.001$ \\
\hline Disorders of adult personality \& behaviour & $\begin{array}{l}\text { F60- } \\
\text { F69 }\end{array}$ & $1.7 \%$ & $0.7 \%$ & $\leq 0.001$ \\
\hline
\end{tabular}
- ICD-10 International Statistical Classification of Diseases \& Related Health Problems, Tenth Revision, Chapter V: Mental \&
behavioural disorders- F00-F99

- Data are (\%) of cases within groups

With respect to any admission to a psychiatric facility, there were no significant differences between cohort 1 and $2(1.03 \%$ vs $1.09 \%, p=0.44$ ), however significant differences were noted in regard to diagnosis types (Table 7). For instance, women admitted to RPS were more likely to have a diagnosis of a mood affective disorder $(50.0 \%$ vs $39.0 \%, p<0.001)$ and/or a disorder of adult personality and behaviour ( $33.5 \%$ vs $23.9 \%, p<0.001)$ when compared to women not admitted to RPS. Women in cohort 1 were however less likely to have mental and behavioural issues arising as a consequence of psychoactive substance abuse $(71.0 \%$ vs $89.0 \%, p<0.001)$ and schizophrenia, schizotypal or delusional disorders $(11.3 \%$ vs $19.1 \%, p<0.001)$. These differences are represented in figure 1 , along with the findings for neurotic, stress-related and somatoform disorders $(p=0.05)$. It was also interesting to note that over the 12-year study period, it was observed that there was an overall $7 \%$ increase in the number of women in cohort 1 having a psychiatric diagnosis noted on their RPS admissions (Figure 2).

Table 7: ICD-10-AM coding assigned to women admitted to psychiatric facilities comparing RPS and non-RPS cohorts 


\begin{tabular}{|c|c|c|c|c|}
\hline ICD-10-AM coding description & Codes & $\begin{array}{l}\text { Residential } \\
\text { admissions } \\
\mathrm{n}=284\end{array}$ & $\begin{array}{l}\text { Non-residential } \\
\text { admissions } \\
\mathrm{n}=6323\end{array}$ & $\begin{array}{l}P \\
\text { value }\end{array}$ \\
\hline Organic, including symptomatic, mental disorders & $\begin{array}{l}\text { F00- } \\
\text { F09 }\end{array}$ & $0.4 \%$ & $0.8 \%$ & 0.02 \\
\hline $\begin{array}{l}\text { Mental \& behavioural issues due to psychoactive substance } \\
\text { abuse }\end{array}$ & $\begin{array}{l}\text { F10- } \\
\text { F19 }\end{array}$ & $71.0 \%$ & $89.0 \%$ & $<0.001$ \\
\hline Schizophrenia, schizotypal \& delusional disorders & $\begin{array}{l}\text { F20- } \\
\text { F29 }\end{array}$ & $11.3 \%$ & $19.1 \%$ & 0.001 \\
\hline Mood affective disorders & $\begin{array}{l}\text { F30- } \\
\text { F39 }\end{array}$ & $50.0 \%$ & $39.0 \%$ & $<0.001$ \\
\hline Neurotic, stress-related \& somatoform disorders & $\begin{array}{l}\text { F40- } \\
\text { F48 }\end{array}$ & $43.0 \%$ & $49.1 \%$ & 0.05 \\
\hline $\begin{array}{l}\text { Behavioural syndromes associated with psychological } \\
\text { disturbances \& physical factors }\end{array}$ & $\begin{array}{l}\text { F50- } \\
\text { F59 }\end{array}$ & $5.6 \%$ & $4.1 \%$ & 0.26 \\
\hline Disorders of adult personality \& behaviour & $\begin{array}{l}\text { F60- } \\
\text { F69 }\end{array}$ & $33.5 \%$ & $23.9 \%$ & $<0.001$ \\
\hline Mental retardation & $\begin{array}{l}\text { F70- } \\
\text { F79 }\end{array}$ & $1.4 \%$ & $1.1 \%$ & 0.85 \\
\hline Disorders of psychological development & $\begin{array}{l}\text { F80- } \\
\text { F89 }\end{array}$ & $0.7 \%$ & $0.5 \%$ & 0.74 \\
\hline $\begin{array}{l}\text { Behavioural \& emotional disorders with onset usually occurring I } \\
\text { childhood \& adolescence }\end{array}$ & $\begin{array}{l}\text { F90- } \\
\text { F98 }\end{array}$ & $2.8 \%$ & $1.9 \%$ & 0.38 \\
\hline Unspecified mental disorder & F99 & $0.0 \%$ & $0.0 \%$ & \\
\hline
\end{tabular}

- Data are (\%) of cases within groups

\section{Discussion}

This is the largest study to date examining the characteristics of women and babies admitted to RPS in NSW who also had a coadmission in the year following birth. The comparison of this cohort to women not admitted to RPS but also having a hospital admission during the same time period is unique to this study. We found that the women who attended RPS in NSW and had a co-admission in the year following birth were slightly older, and more likely to be born in Australia, a private patient when admitted, socially advantaged (higher SEIFA index) and having their first baby. We also identified that these women had higher rates of birth intervention and increased incidences of co-admissions and treatment for mental health disorders.

\section{Socio demographics}

Even though these women were identified as socially and economically advantaged they may still have lacked the necessary social supports to develop confidence in their ability to parent while adjusting to the parenting role and changes in lifestyle that are required with motherhood (37). Lack of functional support from family, friends or community has frequently been indicated as an issue for mothers admitted to RPS $(29,38)$. This type of support is consistent with that provided to women admitted to RPS and includes informational, instrumental, emotional and appraisal support (39), which has been demonstrated to positively influence parenting self-efficacy and lessen the likelihood of experiencing postnatal depression symptoms (39).

\section{Birth intervention}

The significantly increased likelihood of experiencing birth intervention and a caesarean section in the RPS group may have been due to increased complexity in these pregnancies, yet there was no higher incidence of diabetes or hypertension; and smoking was in fact significantly lower. Rather, these factors have been shown to be more related to women who are socially advantaged

Page $12 / 19$ 
and receiving private obstetric care in Australia (40), despite evidence of increased morbidity for these babies (especially in regard to scalp trauma) and with no perinatal advantage $(41,42)$. There is also increasing evidence that women who experience higher rates of medical intervention during labour and birth are more likely to suffer from birth trauma (31) and postnatal depression and have babies affected by gastro-oesophageal reflux and settling and sleeping disorders (30). It was of interest to note that the higher rates of birth intervention in the RPS group was significantly associated with increased SCN/NICU admissions, and lower Apgar for babies, but lower mortality rates, most likely due to their social advantage.

\section{Mental health}

We found significantly more women who had been admitted to RPS had hospital admissions for mood, stress-related, personality and behavioural disorders/syndromes, as well as inpatient admissions to psychiatric facilities. These results are consistent with previous research that demonstrated significant levels of depression and anxiety amongst women admitted to RPS (43-45) [XXXX et al., 2021, manuscript under review].

While women experiencing significant mental illnesses may have developed these prior to pregnancy or birth $(46,47)$, the perinatal period is recognised as a time of particular vulnerability for onset and/or exacerbation of mental health conditions (48). Consequently, routine antenatal screening for mental health disorders has been introduced into Australian public hospitals (49), however screening appears not to be as widely implemented in private settings $(49,50)$. Further education of potential postnatal difficulties may also be beneficial for mothers at this time, as approximately one in five Australian women with a full-term infant have symptoms of a mental health condition or meets the Diagnostic and Statistical Manual of Mental Disorders (DSM-V) criteria for perinatal mental illness in the first year following birth (51-53). It has also been estimated that two thirds of postnatal women with depression or anxiety were symptomatic during pregnancy, with migrant women more likely to be affected with postnatal depression (24-42\% compared to $10-15 \%)(52,54,55)$.

According to a recent NSW study, severe psychiatric disorders resulting in hospital admissions of primiparous mothers within the first-year post-birth have increased significantly over the time period from 2001-2010, with rates of admission at the latter end of this period occurring in just over $2 \%$ of women (56). We also observed a $7 \%$ increase in the proportion of women having a psychiatric diagnosis recorded on their RPS admission between 2000-12. The most common reasons for these admissions were mood affective, and personality and behavioural disorders.

We recently conducted an integrated review of 40 studies assessing RPS within Australia, in which we confirmed mental health issues arising as a consequence of or exacerbated by parenting difficulties are common and associated with disturbed infant feeding, behaviour, sleep and settling [XXXX et al., 2021 manuscript under review]. We also found these issues were coupled with negative reproductive experiences; compromised physical health; stress, lack of support and/or other psychosocial risk factors; fatigue; low self-efficacy; and poor relationship quality amongst parents; and thereby increasing life complexity [Dahlen et al., 2021 manuscript under review]. Further compounding of these factors can also occur as a consequence of fatigue (57) and mental illness decreasing maternal sensitivity and the ability of parents to provide their infants with the necessary consistent and sensitive care that is required $(43,58)$.

While RPS predominately focus on the care of the infant and the developing parent-infant relationship, it also enables mothers (and in some cases fathers) to receive mental health assessment and referral to specialist mental health professionals and services. The initial perceived focus on the infant may facilitate the subsequent seeking of parenting and mental health assistance by reducing the fear of consequence and stigma associated with disclosing mental illness and parenting difficulties (59). These ideas are consistent with the Australian government's emphasis on mental health and social inclusion; early intervention; service access and recovery; continuity of care; and management coordination. While much work has been done in the area of mental health, more is needed to ensure all parents, regardless of their socioeconomic status, have access to appropriate support and treatment services.

\section{Physical health}

It would appear that there is an increasing proportion of women becoming pregnant with existing chronic health issues, such as diabetes, obesity and cardiac disease $(60,61)$. The incidence of physical health problems arising after birth is also on the rise and reportedly due to a range of complex factors, inclusive of social issues, the increasing administration of birth interventions, and a

Page 13/19 
bi-directional relationship with maternal mental disorders $(62,63)$. Caesarean section rates for example are increasing $(64,65)$, as are the associated morbidities of haemorrhage requiring a hysterectomy, uterine rupture, major puerperal infection, venous thromboembolism, cardiac arrest, renal failure, obstetric shock, and in the longer-term, pelvic adhesions and bowel obstructions (65). Severe perineal trauma resulting in pain, incontinence and painful urination is also more common and not surprisingly associated more with instrumental birth.

\section{Limitations}

This paper examines admissions to hospitals and residential parenting facilities only and therefore is limited by the fact that visits to general practitioners, community based and outpatient facilities are not included in the linked dataset.

It is not possible to draw a direct link between higher rates of intervention during the birth and increased likelihood of having an admission to a RPS, as other factors such as having higher socio-economic and education levels that comes with social advantage could lead to an increased uptake of services, especially as these women are also more likely to receive private obstetric care which is associated with increased intervention. The variations in the psychiatric diagnoses of the women accessing RPS may also be an association that is not directly linked and therefore research is needed to further explore this possibility.

\section{Conclusion}

This study is unique in that it examines a complete cohort of women who were admitted to RPS in NSW that also had coadmissions to hospitals within the first-year post-birth and compares them to women who were not admitted to RPS but had a hospital admission during the same time period. Findings demonstrated that women who accessed RPS in the first year after birth were more often first-time mothers, socially advantaged, having higher birth intervention and more co-admissions and treatment for mental health disorders than those in who did not access RPS. More research is needed to explore the impact of birth intervention on mental health issues and subsequent parenting difficulties.

\section{Abbreviations}

APDC - Admitted Patient Data Collection

CHeReL - Centre for Health Record Linkage

DSM - Diagnostic and Statistical Manual of Mental Disorders

HREC - Health Services Research Ethics Committee

ICD - International Classification of Diseases

IVF - In-vitro Fertilisation

NICU - Neonatal Intensive Care Unit

NSW- New South Wales

PDC - Perinatal Data Collection

RBDM - Registry of Births, Deaths and Marriages

RPS - Residential Parenting Services

SCN - Special Care Nursery

SEIFA - Socio-Economic Indexes for Areas 


\section{Declarations}

Ethics approval and consent to participate

All methods were carried out in accordance with relevant guidelines and regulations. As this was not an interventional study, and routinely collected population and health related data was retrospectively obtained from the NSW CHeReL collections, informed consent for participation was waived by NSW Population and Health Services Research Ethics Committee. Ethics approval for all aspects of this study was sought and granted from the NSW Population and Health Services Research Ethics Committee, $\mathrm{HREC} / 10 / \mathrm{CIPHS} / 96$.

\section{Consent for publication}

Not applicable.

Availability of data and materials

Data is available from the NSW CHeReL. Further details can be obtained from the corresponding author.

Competing interests

The authors wish to declare no competing interests.

\section{Funding}

Funding for this study was provided in the form of an Australian Research Council (ARC) Linkage Grant.

Authors' contributions

XX conceived of the study and contributed to the analysis and writing of the manuscript. XX conducted data extraction and analysis. $\mathrm{XX}$ assisted in data verification and contributed to the manuscript. $\mathrm{XX}, \mathrm{XX}$ and $\mathrm{XX}$ contributed to the writing of the manuscript. All authors read and approved the final manuscript.

\section{Acknowledgements}

The authors wish to acknowledge the Australian government for funding of this ARC Linkage study LP130100306.

\section{References}

1. Tresillian. Annual Report. 2019.

https://www.tresillian.org.au/media/1941/tresillian_annualreport_2019_web_revised_jan14.pdf. Accessed 17 Oct 2021.

2. Karitane. Annual Report. 2019. https://karitane.com.au/stores/_sharedfiles/Annual_Report/KaritaneAnnualReport2019_FINALWEB.pdf. Accessed 17 Oct 2021.

3. NSW Ministry of Health. Mothers and Babies 2019,. Centre for Epidemiology and Evidence; 202109 April 2021. https://www.health.nsw.gov.au/hsnsw/Pages/mothers-and-babies-2019.aspx. Accessed 17 Oct 2021.

4. Karitane. Annual Report. 2020. https://karitane.com.au/stores/_sharedfiles/K005_AnnualReport_Online.pdf. Accessed 4 Sep 2021.

5. Fisher J, Rowe H. Building an evidence base for practice in early parenting centers. A systematic review of the literature and a report of an outcome study. Key Centre for Women's Health in Society, School of Population Health, University of Melbourne. 2004.

6. Rowe HJ, Fisher JRW. The contribution of Australian residential early parenting centres to comprehensive mental health care for mothers of infants:evidence from a prospective study. Int. J. Ment. Health Syst. 2010;4:6 
7. Kohlhoff J, Barnett B. Parenting self-efficacy: links with maternal depression, infant behaviour and adult attachment. Early Hum. Dev.. 2013;89(4):249-56.

8. Berry K, Jeon Y-H, Foster K, Fraser J. Extended parenting education in an early parenting centre: a mixed-methods study. J. Child Health Care. 2015, 20(4): 446-55.

9. Buist A, Bilszta J. The beyondb/ue national postnatal depression program. Prevention and early intervention 2001-2005. Final report. Vol.1. 2005.

10. Perinatal Anxiety and Depression Australia (PANDA). Submission to the productivity commission mental health Inquiry: the social and economic benefits of improving perinatal mental health. 2019. https://www.pc.gov.au/_data/assets/pdf_file/0005/240908/sub344-mental-health.pdf. Accessed 9 Apr 2021.

11. Milgrom J, Ericksen J, McCarthy R, Gemmill AW. Stressful impact of depression on early mother-infant relations. Stress Health. 2006;22(4):229-38

12. Sayil M, Gure A, Ucanok Z. First time mothers' anxiety and depressive symptoms across the transition to motherhood: associations with maternal and environmental characteristics. Women Health. 2006;44(3):61-77.

13. Giallo R, Cooklin A, Zerman N, Vittorino R. Psychological distress of fathers attending an Australian early parenting service for early parenting difficulties. Clin Psychol. 2013;17(2):46-55.

14. Wynter K, Wilson N, Thean P, Bei B, Fisher J. Psychological distress, alcohol use, fatigue, sleepiness, and sleep quality: an exploratory study among men whose partners are admitted to a residential early parenting service. Aust Psychol. 2019; 54:143-50.

15. Christl B, Reilly N, Yin C, Austin M-P. Clinical profile and outcomes of women admitted to a psychiatric mother-baby unit. Arch Womens Ment Health. 2015;18(6):805-16.

16. Nair R, Bilszta J, Shafira N, Salam N, Buist A. Review of patients admitted to a specialist inpatient parent-infant psychiatric service. Australas. Psychiatry. 2010;18(6):567-72.

17. McCain M, Mustard JF. The early years study three years later: from early child development to human development: enabling communities. Toronto: Canadian Institute for Advanced Research. 2002.

18. Waylen A, Stewart-Brown S. Factors influencing parenting in early childhood: a prospective longitudinal study focusing on change. Child Care Health Dev . 2010;36(2):198-207.

19. Bauer A, Knapp M, Parsonage M. Lifetime costs of perinatal anxiety and depression. J Affect Disorders. 2016;192:83-90.

20. Plant DT, Pawlby S, Sharp D, Zunszain PA, Pariante CM. Prenatal maternal depression is associated with offspring inflammation at 25 years: a prospective longitudinal cohort study. Transl. Psychiatry. 2016;6:e936.

21. Stein A, Pearson R, Goodman S, Rapa E, Rahman A, McCallum M, et al. Effects of perinatal mental disorders on the fetus and child. Lancet. 2014;384(9956):1800-19.

22. Lazinski MJ, Shea AK, Steiner M. Effects of maternal prenatal stress on offspring development: a commentary. Arch Womens Ment Health. 2008;11(5-6):363-75.

23. Gentile S, Fusco ML. Untreated perinatal paternal depression: effects on offspring. Psychiatry Res. 2017;252:325-32.

24. Glover V. Maternal depression, anxiety and stress during pregnancy and child outcome; what needs to be done. Best Pract Res Clin Obstet Gynaecol . 2014;28:25-35.

25. Barnett B, Lockhart K, Bernard D, Manicavacagar V, Dudley M. Mood disorders among mothers of infants admitted to a mothercraft hospital. J Paediatr Child Health. 1993;29:270-5.

26. Matthey S, Speyer J. Changes in unsettled infant sleep and maternal mood following admission to a parentcraft residential unit. Early Hum. Dev. 2008;84:623-9.

27. Hammarberg K, Rowe HJR, Fisher JRW. Early post-partum adjustment and admission to parenting services in Victoria, Australia after assisted conception. Hum Reprod. 2009;24(11):2801-9.

28. Dahlen HG, Thornton C, Fowler C, Mills R, O'Loughlin G, Smit J, et al. Characteristics and changes in characteristics of women and babies admitted to residential parenting services in New South Wales, Australia in the first year following birth: a population-based data linkage study 2000-2012. BMJ Open. 2019. http://dx.doi.org/10.1136/bmjopen-2019-030133 
29. Priddis H, Thornton C, Fowler C, Schmied V, Tooher J, Dickinson M, et al. Characteristics and service needs of women and babies admitted to residential parenting units in New South Wales: a mixed-methods study. J. Clin. Nurs. 2018;27(15-

16):2963-73.

30. Dahlen HG, Foster JP, Psaila K, Spence K, Badawi N, Fowler C, et al. Gastro-oesophageal reflux: a mixed methods study of infants admitted to hospital in the first 12 months following birth in NSW (2000-2011). BMC Pediatr.2018;18:30.

31. Priddis HS, Keedle H, Dahlen H. The perfect storm of trauma: the experiences of women who have experienced birth trauma and subsequently accessed residential parenting services in Australia. Women Birth. 2018;31(1):17-24.

32. Simpson M, Schmied V, Dickson C, Dahlen HG. Postnatal post-traumatic stress: an integrative review. Women Birth. 2018; early access online.

33. Australian Bureau of Statistics. Socio-Economic Indexes for Areas (SEIFA). 2018. https://www.abs.gov.au/websitedbs/censushome.nsf/home/seifa. Accessed 10 Sep 2021.

34. Centre for Health Record Linkage. Centre for Health Record Linkage. MLK quality assurance report, 2012. https://www.cherel.org.au/media/24160/qa_report_2012.pdf. Accessed 5 Aug 2020.

35. Commonwealth of Australia. The International Classification Of Diseases and Health Related Problems. Tenth Revision, Australian Modification (ICD-10-AM) 2012 Sydney, Australia. 2012.

36. Australian Government Deapartment of Health. Medicare Benefits Schedules (Complete MBS and MBS by Category). 2020. http://www.mbsonline.gov.au/internet/mbsonline/publishing.nsf/Content/Downloads-202001. Accessed 5 Aug 2020.

37. Fowler C, Rossiter C, Maddox J, Dignam D, Briggs C, DeGuio A-L, et al. Parent satisfaction with early parenting residential services: a telephone interview study. Contemp. Nurse 2012;43(1):64-72.

38. Fowler C, Schmied V, Dickinson M, Dahlen HG. Working with complexity: experiences of caring for mothers seeking residential parenting services in New South Wales, Australia. J. Clin. Nurs. 2017;26(3-4):524-34.

39. Leahy-Warren P, McCarthy G, Corcoran P. First-time mothers: social support, maternal parental self-efficacy and self-efficacy. J. Clin. Nurs. 2011;21:388-97.

40. Dahlen HG, Tracy S, Tracy M, Bisits A, Brown C, Thornton C. Rates of obstetric intervention among low-risk women giving birth in private and public hospitals in NSW: a population-based descriptive study. BMJ Open. 2012;2:e001723 doi:10.1136/bmjopen-2012-001723.

41. Dahlen H, Tracy S, Tracy MB, Bisits A, Brown C, Thornton C. Rates of obstetric intervention and associated perinatal mortality and morbidity among low-risk women giving birth in private and public hospitals in NSW (2000-2008): a linked data population-based cohort study. BMJ Open. 2014;2014;4:e004551. doi:10.1136/bmjopen-2013-004551.

42. Dahlen HG, Thornton C, Downe S, de Jonge A, Seijmonsbergen-Schermers A, Tracy S, et al. Intrapartum interventions and outcomes for women and children following induction of labour at term in uncomplicated pregnancies: a 16-year populationbased linked data study. BMJ Open. 2021;11(6):e047040.

43. McMahon C, Barnett B, Kowalenko N, Tennant C, Don N. Postnatal depression, anxiety and unsettled infant behavior. Australian and New Zealand Journal of Psychiatry. 2001;35(5):581-8.

44. Christi B, Reilly N, Smith M, Sims D, Chavasse F, Austin M-P. The mental health of mothers of unsettled infants: is there value in routine psychosocial assessment in this context? Arch Womens Ment Health. 2014;16(5):391-9.

45. Phillips J, Sharpe L, Matthey S. Rates of depressive and anxiety disorders in a residential mother-infant unit for unsettled infants [corrected] [published erratum appears in Aust N Z J Psychiatry2009 Nov;43(11):1087]. Aust N Z J Psychiatry 2007;41(10):836-42.

46. Paschetta E, Berrisford G, Coccia F, Whitmore J, Wood A, Pretlove S, et al. Perinatal psychiatric disorders: an overview. Am. J. Obstet. Gynecol. 2014;June:501-9.

47. Rubertson C, Hellström J, Cross M, Sydsjö G. Anxiety in early pregnancy: prevalence and contributing factors. Arch Womens Ment Health. 2014;17:221-8.

48. Biaggi A, Conroy S, Pawlby S, Pariante CM. Identifying the women at risk of antenatal anxiety and depression: a systematic review. J. Affect. Disord 2016;191:62-77. 
49. Kohlhoff J, Cibralic S, Tooke S, Hickinbotham R, Knox C, Roach V, et al. Health professional perspectives on an antenatal mental health screening program in a private hospital. Aust N Z J Obstet Gynaecol. 2021; 1-7.

50. Reilly N, Brake E, Kalra H, Austin MP. Insights into implementation of routine depression screening and psychosocial assessment in a private hospital setting: a qualitative study. Aust N Z J Obstet Gynaecol . 2020;60(3):419-24.

51. Austin MP, Priest SR, Sullivan EA. Antenatal psychosocial assessment for reducing perinatal mental health morbidity. Cochrane Database Syst Rev 2008; 4.

52. Neale A, Wand A. Issues in the evaluation and treatment of anxiety and depression in migrant women in the perinatal period. Australas. Psychiatry. 2013;21(4):379-82.

53. Shafiei T, Biggs LJ, Small R, McLachlan HL, Forster DA. Characteristics of women calling the PANDA Perinatal Anxiety \& Depression Australia national helpline: a cross-sectional study. Arch Womens Ment Health. 2018:1-12.

54. Zelkowitz P, Saucier JF, Wang T, et al. Stability and change in depressive symptoms from pregnancy to two months postpartum in childbearing immigrant women. Arch Womens Ment Health. 2008;11:1-11.

55. Collins $\mathrm{CH}$, Zimmerman C, Howard LM. Refugee, asylum seeker, immigrant women and postnatal depression: rates and risk factors. Arch Womens Ment Health. 2011;14:3-11.

56. Xu F, Sullivan EA, Li Z, Burns L, Austin M-P, Slade T. The increased trend in mothers' hospital admissions for psychiatric disorders in the first year after birth between 2001 and 2010 in New South Wales, Australia. BMC Womens Health. 2014;14(1):119.

57. Giallo R, Rose N, Vittorino R. Fatigue, wellbeing and parenting in mothers of infants and toddlers with sleep problems. J Reprod Infant Psychol . 2011;29(3):236-49.

58. Siqveland T, Smith L, Moe V. The impact of optimality on maternal sensitivity in mothers with substance abuse and psychiatric problens and their infants at 3 months. Infant Behav Dev . 2012;35:60-70.

59. Small R, Taft AJ, Brown SJ. The power of social connection and support in improving health: lessons from social support interventions with childbearing women. BMC Public Health. 2011;11S4.

60. Bick D, Beake S, Chappell L, Ismail KM, McCance DR, Green JS, et al. Management of pregnant and postnatal women with pre-existing diabetes or cardiac disease using multi-disciplinary team models of care: a systematic review. BMC Pregnancy Childbirth 2014;14(1):1-13

61. Abouzeid M, Versace VL, Janus ED, Davey M-A, Philpot B, Oats J, et al. A population-based observational study of diabetes during pregnancy in Victoria, Australia, 1999-2008. BMJ Open. 2014;4(11).

62. Woolhouse H, Gartland D, Perlen S, Donath S, Brown SJ. Physical health after childbirth and maternal depression in the first 12 months post partum: results of an Australian nulliparous pregnancy cohort study. Midwifery. 2014;30(3):378-84.

63. Schmied V, Bick D. Postnatal care - Current issues and future challenges. Midwifery. 2014;30(6):571-4.

64. Betrán AP, Ye J, Moller A-B, Zhang J, Gülmezoglu AM, Torloni MR. The increasing trend in caesarean section rates: global, regional and national estimates: 1990-2014. PloS one. 2016;11(2):e0148343.

65. Fox H, Callander E, Lindsay D, Topp S. Evidence of overuse? Patterns of obstetric interventions during labour and birth among Australian mothers. BMC Pregnancy Childbirth. 2019;19(1):226.

\section{Figures}




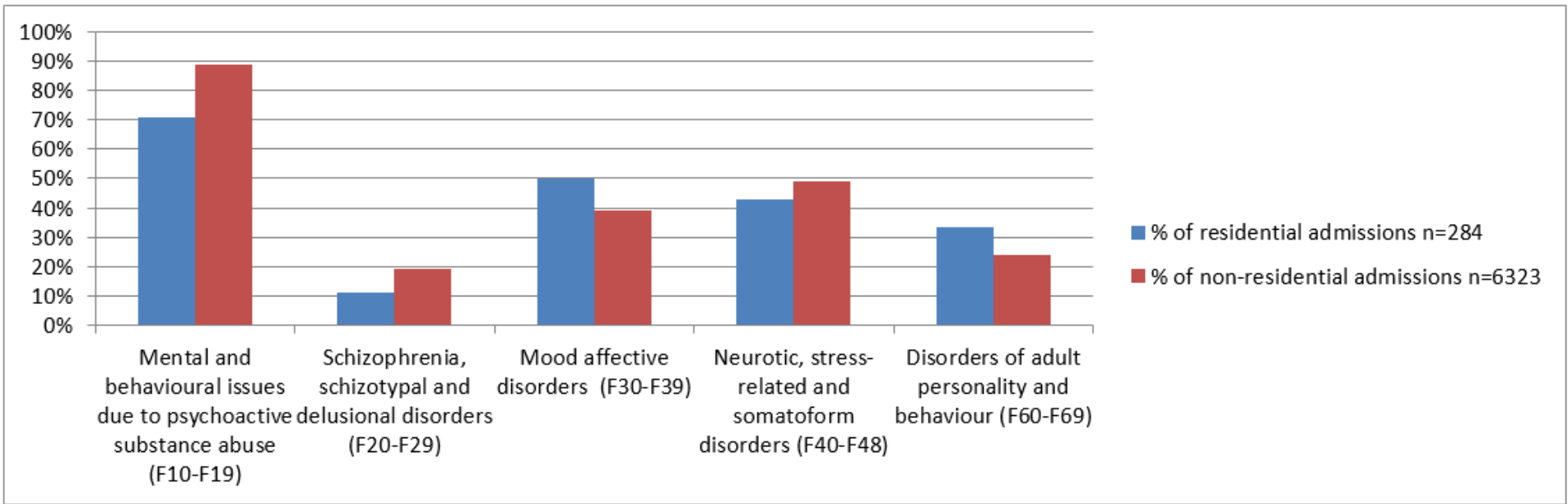

Figure 1

Five most common psychiatric codes assigned to women admitted to psychiatric facilities between women who were also admitted to RPS and those who were not

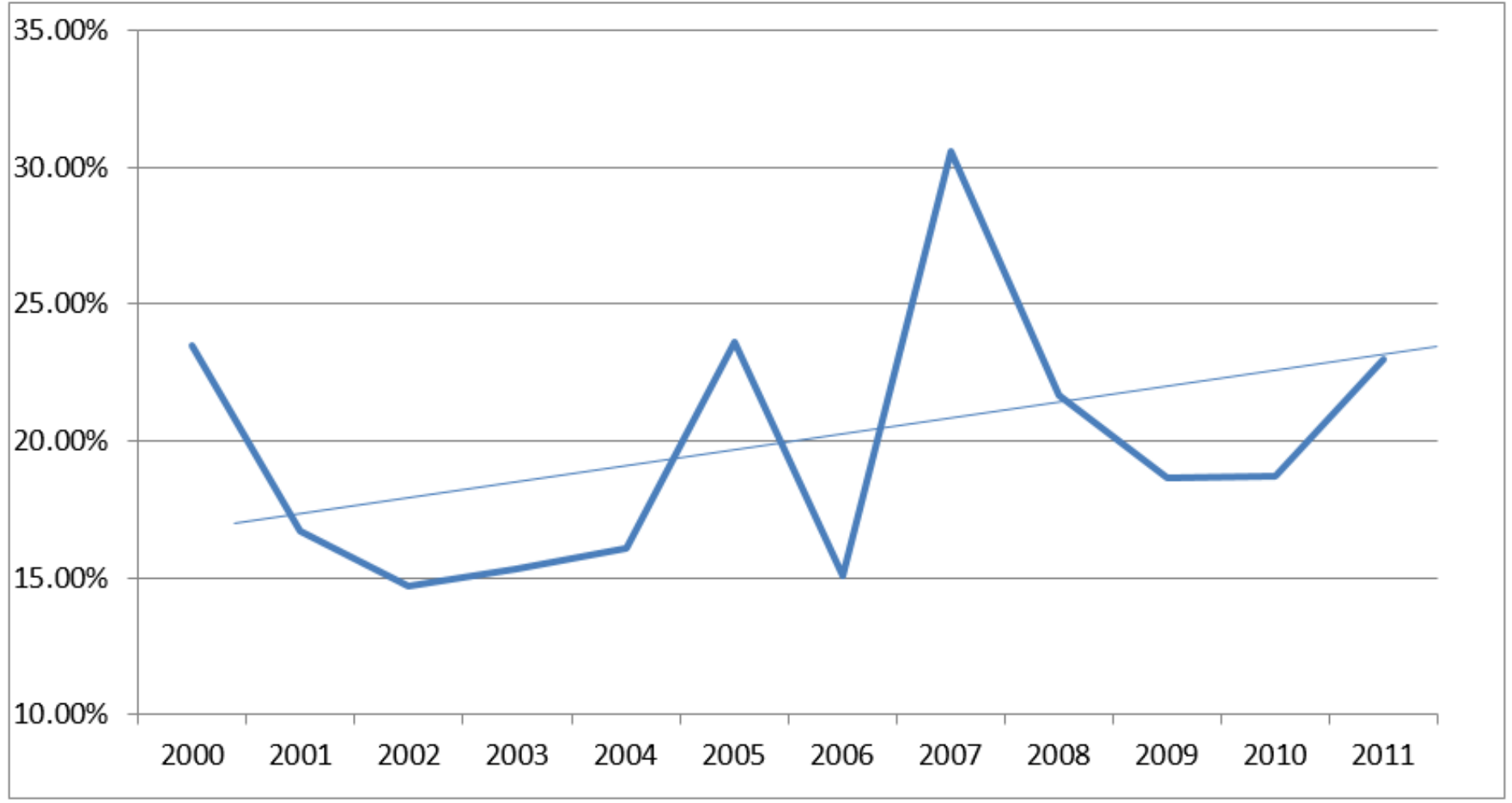

Figure 2

Psychiatric ICD-10-AM codes as a percentage of all coding of admissions to residential units expressed over time -ICD-10-AM International Statistical Classification of Diseases \& Related Health Problems, Tenth Revision, Australian Modification (ICD-10AM) used to classify diseases \& other health problems 